\title{
A Fifteen Year Review Summarizing Effects of Conventional and Organic Farming Systems on Soils, Nutrition, Environment, Economics and Yields (1981-1995)
}

\author{
Jeff Moyer, Kris Nichols and Vijay Bhosekar* \\ Rodale Institute, USA
}

Submission: March 03, 2017; Published: April 21, 2017

*Corresponding author: Vijay Bhosekar, Rodale Institute, Kutztown, Pennsylvania, 19530, USA, Email: vijaybhosekar@gmail.com

\begin{abstract}
The principal assumptions to the proposition that organic agriculture could contribute significantly to the global food supply are, low yields and insufficient quantities of organically acceptable fertilizers. A critical 15 year review on both the issues studied showed that, organic yields were comparable to conventional practices after a transition period ( $\sim 5$ years). The review also indicated that global food supply could be grown organically on the current agricultural land base. Furthermore, it is evidenced that, organic methods could produce enough food on a global per capita basis to sustain the current human population without increasing the arable land. This critical review also suggested that, organic agriculture has the potential to contribute quite substantially to the global food supply, while reducing the detrimental environmental impacts of conventional agriculture.
\end{abstract}

Keywords: Organic; Conventional; Economics; Soils and environment

\section{Introduction}

Heavy agricultural reliance on synthetic/chemical fertilizers and pesticides is having serious impacts on public health and the environment [1]. It was reported by Greene [2] that, excessive fertilizer use costs $\$ 2.5$ billion from wasted fertilizer inputs and modern agricultural practices are also a concern related to soil erosion.

Integrated pest and nutrient management systems and organic agriculture could minimize reliance on agrichemical inputs, as well as making agriculture environmentally and economically sound. Further Altieri et al. [3] demonstrated that sound sustainable management practices reduced pesticide usage, while maintaining comparable crop yields with improved farm economy.

This review study also revealed that, Organic agriculture seeks to augment ecological processes that foster plant nutrition while conserving soil and water resources. In addition to, Organic systems eliminated synthetic fertilizers and reduced other external inputs improving the environment and hence the farm sustainability.
Since 1981, Rodale Institute Farming Systems Project carried out comparative studies on Organic and Conventional Cropping Systems and the highlight achievements/progress during the period (till 1995) are projected under various major components/parameters -Nutrition, Soils, Environment, Economics and Yields. The exhaustive information provided in this Review Article could provide a vital and regenerative tool for developing agricultural framework in tune with environment, while motivating farming community to adapt Sustainable Farming Systems with comparable yields to conventional systems.

\section{Nutrition}

Studies suggested that, maintaining acceptable crop yields depended to a great extent on nutrient supply in appropriate/ sufficient quantities, and at the right times, supporting growth of plants. To achieve top yields, conventional agriculture has relied heavily on commercial fertilizers to provide essential nutrients, especially nitrogen.

The ready availability of nitrogen fertilizers has supported crop yields since the 1940s, but the abundance afforded by 
commercial fertilizers comes at a price. The industrial fixation of nitrogen for fertilizer is the largest human contribution of new nitrogen to the global nitrogen cycle, and is a significant contributor to environmental problems, including acid rain and the greenhouse effect [4].

A major goal of the Farming System Trial had been to determine if adequate and stable nutrient levels could be achieved without application of commercial fertilizers, asin organic systems that used either manure or nitrogen-fixing legume crops in rotation with cash crops.

In the early years of the trial, nitrogen levels in the two organic systems clearly were not adequate to produce yields of corn-used as the benchmark crop because of its heavy requirements for nitrogen that were equivalent to the conventional system. In the first year of the trial, the legume-based system produced $56 \%$ of the corn yield of the conventional system, and the manure-based system produced $64 \%$. These are in conformity with findings of [5].

Nitrogen deficiencies in the organic systems were to be expected at the outset, because the experimental area had been in corn and wheat, rather than nitrogen-fixing green manures, for several years before the start of the trial. Although the manurebased system received nitrogen in the form of manure, the manure used for the first application had a low nitrogen concentration, which apparently was not released quickly enough to satisfy the corn crop.

The organic systems' yields of soybeans, a leguminous crop that is capable of fixing its own nitrogen, have been equivalentand occasionally higher-than those in the conventional system. The conventional system did not include small grain or hay crops, but yields of those crops in the organic systems were comparable to those achieved on conventional farms in the county [5].

Satisfactory yields of crops other than corn clearly indicated that nitrogen was the limiting factor in the organic systems in the first few years of the trial. Lower levels of plant-available nitrogen may have been indirectly related to management practices as well, including competition from weeds, which were more numerous in the organic systems. Similar studies were reported by Hanson et al. [6].

Practices such as relay cropping also may have depressed yields in the organic systems in the early years, as researchers experimented with relay cropping and different combinations of cover crops, green manures, and cash crops.

After 1984, however, corn yields in the organic systems rose to a level, equivalent to yields in the conventional system and have remained stable for 11 years. Soil tests indicated that plantavailable nitrogen had become more abundant in both organic systems, particularly in the manure-based system, and had declined slightly in the conventional system, which are in tandem with Hanson et al. [6].

A 10-year estimate (1981-91) of nitrogen inputs (in the form of crop residues, animal and green manures, and commercial fertilizers) and nitrogen removed by harvested crops indicated that the legume-based system received about half as much nitrogen as did the other two systems. Further, the legume-based system operated at a nitrogen deficit of about 25lbs. of nitrogen per acre per year, while the manure-based and conventional systems had more nitrogen applied than was removed by crops [1].

This would suggest that nitrogen levels should increase in the manure-based and conventional systems, and should decrease in the legume-based system. In fact, while total soil nitrogen did increase slightly in the manure-based system, it remained level in the legume-based system, and declined slightly in the conventional system.

The higher levels of available nitrogen in the organic systems did not appear to be related to the sheer quantity of organic matter being supplied, but rather to the types and diversity of that organic matter. Both organic systems received large amounts of live plant residue, and the manure-based system received animal waste as well. The conventional system received only crop stubble. It is well documented that live plant residues and animal wastes contain a higher proportion of nitrogen, relative to carbon, than does dead plant residue.

Significantly, the green manures in the legume-based system also appeared to provide more nitrogen during the critical growth phase of corn (mid-June to August) than did commercial fertilizer applied at the same time.

Soils

It is well documented that soil fertility and soil quality is based on microbes that cycle nutrients from decaying organic material into inorganic forms that can be used by growing plants. Thus, play a role in forming soil structure, binding soil minerals and organic matter into soil aggregates [4].

Hepperly et al. [7] reported that as early as 1986, microbial biomass and activity were greater in the Farming System Trial's manure-based system, and to a lesser degree in the legumebased system, than in the conventional system. This is for obvious reason that, the partly decomposed animal wastes applied to the manure-based system had microorganisms, and both the legumebased and manure-based systems received organic residues that were relatively high in nitrogen, which is known to spur microbial activity.

It is generally observed that, practices in most agricultural systems have led to a loss in soil organic matter, either because inadequate amounts of organic materials were added to the soils or because the turnover rate was exceptionally high. For a farming system to be stable and sustainable, microbial activity must make nutrients available for the short-term benefit of plants, but not at the long-term expense of soil organic matter [7]. The turnover rate must be high enough to support reasonable crop yields, but some of the organic materials must also be converted to more stable humus, which can absorb and act as a reservoir of nutrients. 


\section{Microbial activity}

The results also revealed that, measurable changes in microbial biomass and activity in the organic systems occurred very quickly, possibly because of the relatively high-nitrogen nature of the organic residues supplied to those systems. The manure-based system consistently showed the highest rate of microbial activity, the conventional system the least [8].

Franke-Snyder et al. [8] also reported that, microbial communities proliferated and declined through the season in all the systems, depending largely on soil temperatures and whether or not the soil had recently been tilled or cultivated. The process of decay progresses more quickly under warm conditions (late spring/early summer), and soil disturbances increase the rate of decomposition. But microbial activity also appeared to be affected by the type of crop being grown.

Drinkwater et al. [9] reported that, during the above season (spring/summer), the legume-based system, planted to a green manure crop of hairy vetch, had $15 \mathrm{~kg}$ per acre more microbial biomass than the manure-based or conventional systems. Furthermore, in the same growing period, a week after the vetch had been plowed down, microbial biomass in that plot was equal to that in the manure-based system, and both showed slightly higher microbial biomass than the conventional system. Furthermore, similar trend of results in 1988 and 1990 showed that, both the organic systems had larger pools of active biomass-microorganisms and plant-available nutrients-than the conventional system.

Further, researchers also compared microbial activity in a conventional plot with two different plots in the legume-based system-one with a cover crop of hairy vetch, and the other with corn stubble and the remains of an inter seeded rye crop. It was observed changes in the soil microbial community were most pronounced in the plot with the vetch cover crop. This is in tune with findings of Wander et al. [10].

\section{Nitrogen levels}

The results also revealed that, changes in total soil nitrogen occurred slowly in all three systems, but at the end of 15 years, both of the organic systems showed an increase in soil nitrogen while the conventional system showed a decrease. Also, the manure-based system's level of soil nitrogen was highest overall.

Hepperly et al. [7] reported that, nitrogen increased in the legume-based system even though it had received fewer nitrogen inputs than either of the other two systems, an indication that a thriving soil community is converting organic materials into forms useable by plants. A possible explanation for the higher nitrogen levels in the organic systems is that live plants, which can take up and store nitrogen, are present in those systems for much more of the year, than they are in the conventional system (73\% and $70 \%$, respectively, for the manure-based and legumebased systems, versus $42 \%$ in the conventional system.

\section{Soil carbon}

The results also revealed that, despite their greater biological activity, both organic systems also accumulated carbon, an indication that they are not "using up" their soil organic matter, whereas, the conventional system showed little net gain in carbon. The increase in carbon levels was particularly significant in the legume-based system, because that system had received less carbon in the form of inputs than either of the other two systems [9].

Moreover, the legume-based system showed the highest level of stable organic matter, and a study of soil analysis found that the legume-based system had significantly lower amounts of carbon in water-soluble form, which can be leached from the soil. This finding suggests that farming systems using cover crops in rotation can benefit the environment by serving as carbon "sinks" to absorb and store carbon released by other human activities [9].

Hepperly et al. [7] also suggested that, the manurebased system, which received carbon inputs equivalent to the conventional system, appeared to be turning over nutrients at the fastest rate. Yet, like the legume-based system, it did not show a loss in nitrogen or carbon despite its high rate of microbial activity. A factor in the ability of the manure-based system to maintain its organic matter content may have been that, its soils were plowed less often than those in the legumebased system. Soil disturbances, whether from plowing or cultivating, stimulate microbial activity, which can free nutrients but also can decrease organic matter.

\section{Environmental Impact}

Agriculture is a major force in the environment, partly because of the amount of land devoted to it globally (nearly a third of the Earth's land surface is used for agricultural or grazing purposes), and partly because of modern, intensive production systems that emphasize the use of pesticides and chemical fertilizers.

Many of the environmental impacts are essentially local or regional, such as pollution in the form of pesticides, excess nutrients, and eroded soil that can contaminate groundwater and surface water supplies. In recent years, it has become clear that agricultural practices also affect the global environment, especially in terms of the global cycling of carbon and nitrogen [1].

In the early years (1981-1988) of the Farming Systems Trial, measurements of the environmental impact of agriculture focused largely on how different farming practices used and conserved resources, particularly nitrogen sources and water. In later years (1989-1995), emphasis turned toward understanding how nitrogen and carbon were cycled through the soils of the different farming systems. 
The first five years demonstrated that organically managed systems were capable of producing and retaining sufficient nitrogen to support high production levels without the use of industrially produced fertilizers. Organically managed soils also demonstrated better ability to retain moisture during dry periods, an important consideration in conserving water resources and preventing soil erosion. These are in conformity with [5].

Lotter et al. [5] also reported that over the years (19901995) certain management practices in the organic systems may also play a central role in protecting the global environment, and as the years progressed, differences in soil nitrogen and carbon content among the three systems began to be noticeable. Furthermore, soil nitrogen was initially (1981-1986) highest in the conventional system and lowest in the legume-based system and by 1991, soil nitrogen was greatest in the manure-based system and lowest in the conventional.

The trend in soil nitrogen was important in determining whether organically managed systems could sustain production over the long term, but it also raised important questions about the long-term environmental impact of agricultural practices. Over 15 years, the amount of nitrogen put into the conventional system, through fertilizer and crop residues, outweighed the amount taken out by harvested crops, yet the amount of nitrogen in the conventionally managed soils decreased by $11 \%$. These are in tune with findings of [11].

Harris et al. [11] also reported that, while the conventionally managed system would produce adequate yields even after 15 years, measurements of soil nitrogen indicated, that the soil is gradually becoming more impoverished, and future yields may depend more heavily on nitrogen inputs.

Power et al. [12] opined that, in the manure-based system, soil nitrogen inputs, in the form of manure and crop residues, also outweighed the amount taken out by crops. But soil nitrogen levels increased in the manure-managed system by nearly the amount of the surplus, suggesting that little nitrogen is being lost under that regimen.

Galvez et al. [13] justified that, in the legume-based system, nitrogen inputs in the form of cover crops and residues was less than in either the manure-based or conventional systems-an average of $25 \mathrm{Kg}$ of nitrogen per acre each year versus an average of $40 \mathrm{Kg}$ of nitrogen per acre each year for the other two systems. The amount of nitrogen removed by harvested crops was roughly equivalent to the amount of nitrogen supplied. Yet soil nitrogen levels have not changed significantly in the legume-based system, suggesting that the system is efficiently cycling nitrogen into growing crops. Furthermore, the study also revealed that the conventionally managed system lost $50 \%$ more nitrogen in the form of nitrates than the manure-based system did, and $150 \%$ more than the legume-based system.
Harris et al. [11] opined that, the lower rates of nitrate leaching from the organic systems may be linked to the extensive use of cover crops, using nitrogen in the early spring and fall. In the conventional system, the soil is bare or freshly plowed during those times, possibly contributing to a higher nitrate leaching rate. Lower rates of nitrogen losses from the organic systems may also relate to other factors that determine how nitrogen is cycled through a farming system. For example, an analysis of the microorganisms in the soils of the various systems found a difference in how soil microbes handle nitrogen from organic versus mineral sources. Nearly twice as much nitrogen derived from legumes remained in the active fraction of soil organic matter a year after a cover crop was tilled in, as compared to nitrogen from commercial fertilizer that was incorporated into the soil at the same time.

When the trial began in 1981, total soil carbon in the upper soil layer was equal across systems which implied that any changes in carbon content could be directly attributed to differences in farming practices. Carbon inputs to the conventional and the manure-based systems were roughly equivalent-the conventional system returned the most carbon in the form of un harvested crop stubble and weeds, but the manure-based system also added carbon in the form of manure. Yet the carbon content of the conventionally managed soil declined over the years, while the carbon content of the manure-based system increased. Similar trend of results were also reported by Mader et al. [14].

These important findings demonstrated that agricultural management practices could minimize the impact of the greenhouse effect, caused principally by excess carbon dioxide in the atmosphere. The legume-based system, however, showed the greatest increase in carbon content, although it received the least carbon in the form of aboveground plant residues [4].

Wander et al. [15] also reported that, the difference in carbonretention abilities of the three systems appeared to be related to the ratio of carbon to nitrogen, as well as to the diversity, in the types of organic materials returned to the soil. Soils that received organic materials that were lower in carbon content relative to nitrogen content (such as legume cover crops and manure) were significantly more efficient at retaining carbon and nitrogen than soils that received only high-carbon organic materials such as dead crop stubble. The additional carbon retention in the legume-based system amounted to between 1 and 2 tons per acre. If similar management practices were widely adopted, that rate would be high enough to absorb from 1 to $2 \%$ of the carbon released into the atmosphere from fossil-fuel combustion in the United States. Furthermore, the two organic systems also released less carbon dioxide into the atmosphere than did the conventional system, largely because of reduced energy use for tillage and cultivation. Further energy use in the conventional system was $200 \%$ higher than in either of the organic systems [15]. 


\section{Economics}

Farming is inherently a risky way to earn a living and profits depend on many factors, not all of which are under the farmer's control. A farmer's management skills and the quality of his or her soil are critical parts of the economic picture, but so is the weather, the costs of production, and the fluctuating market price for harvested crops. Since farmers have little control over the prices they will receive for their crops, many have expressed interest in improving income by reducing production costs instead. Bolstering soil fertility with animal wastes or green manures, instead of purchased fertilizer, is one way to cut costs, as well as, organic systems relying on diverse crop rotations to achieve and maintain soil fertility.

An economic analysis using yield data from the Farming Systems Trial estimated income from the conventional and legume-based systems over a period of nine years (1981-1989), under different scenarios was as follows:

A. Conventional farm, practicing the trial's five-year rotation of corn and soybeans (three of those years in corn, two in soybeans).

B. Conventional farm growing five-year corn/soybeans rotation, but planted each year in either corn or soybeans.

C. Organic farm following the legume-based system's rotation of small grains and forage crops, corn, and soybeans.

D. Organic farm that followed an adapted form of the legume-based system's rotation only.

The study revealed that, scenario (a) had the highest profits lightly over $\$ 39,000$ a year on an average basis. Second was (d) at $\$ 32,400$ annually. Third was (b) at $\$ 29,900$, and (c) was last at $\$ 27,600$ annually. However, the nine years of production used for the analysis included the early years of the trial, when yields in the organic systems were significantly lower than in the conventional system. Similar findings were also reported by Delate et al. [16] and Chavas et al. [17].

Another study with similar scenario as given above, done only for the years from 1986-90, in which yields were equivalent, showed(d) was the most profitable, at more than $\$ 44,000$ a year, and (b) the least profitable at slightly less than $\$ 22,000$ annually. Whereas, (a) showed an average profit of $\$ 34,700$, and (c) showed an average profit of $\$ 32,000$. It also revealed that (c) averaged $\$ 10,000$ more per year in profits after the transition period ( $1981-85$ ) than it did before, largely because average corn yields nearly doubled. This implied that, switching over from conventional to organic farming would have a basic transition period of 4- 5 years before getting more yields. This is in conformity with findings of $[6,18]$.

Studies conducted elsewhere by Brumfield et al. [19] also documented that, though conventional farming benefitted from higher yields and profits in the early 4- 5 years (transition period), but organic farming did have better returns during the latter years as production costs were less. In addition to, whenever there was higher fluctuation in grain prices, organic farming system had a better adaptability, than the conventional ones because they had crop diversity, hence farming community could sustain. In 1986, the organic systems switched to a more intensive three-year rotation to include additional cash grains such as wheat and barley, as well as, hay and straw to sell-lowvalue crops, but marketable crops nonetheless, and one-third of the income from the organic farm came from sources other than corn or soybeans, making it more profitable and sustainable [1].

It was also documented by (Roberts et al., 1979) that, expenses on the organic farms were significantly lower than on the conventional farm and the two conventional farms in the analysis spent about $95 \%$ more each year than the organic farms for fertilizers and pesticides. Overall, production costs on the organic farms were $26 \%$ lower than on the conventional farms, although machinery costs were higher because of the need to purchase and maintain equipment for harvesting hay. Similar trend of results were also reported by Delate et al. [20].

In general, the organic system appeared to be the less risky one, as such profits for the organic farms tended not to be as high as those on the conventional farm in good years, but they weren't as low in bad years, either [21]. At the end of the nineyear period, the study showed that organic farm had increased net worth compared to conventional farm. The higher need for borrowed money in the organic systems reflected the lower yields in the early years, and it reinforces the finding that there is a transition period in switching from conventional practices to organic ones [6].

It was also observed that biological transition in the Farming System Trial took four years. By 1985, the investment in capital was repaid with yields that rose to the level of the conventional system and remained stable, with net profits nearly similar to conventional, and then progressively increased to higher levels. While profits for the organic farms increased as yields improved, economic projections indicated that it would take more than a decade to fully recover the income lost during the biological transition. A second economic analysis, using only the years from 1986 through 1995, when yields from the organic system were equivalent to those from the conventional, showed that the organic farm returned $\$ 13.18$ an acre more in profits from 198690 , and $\$ 6.30$ an acre more from 1991-95. These are in tune with findings of [20].

Studies conducted in Iowa (USA) by Karlen et al. [21] reported that the organic farm's per-acre income advantage decreased as the farm increased in size. At 750 acres, the organic farm showed a $\$ 4,724$ income advantage over the conventional farm for the 1991-95 periods; at 1500 acres, the advantage increased only to $\$ 6,326$.This difference relates to hired labor during periods of intensive field work. The study also demonstrated significant 
disadvantage for organic farms relative to conventional ones: the labor required to operate them. The labor involved in the organic farms tended to be spread more evenly over the year than in the conventional farms, where labor requirements were high during planting and harvesting seasons and low at other times of the year; for July through September, the conventional farm required no field operations at all [21].

The organic farm, which involved mechanical cultivation and the planting and harvesting of a greater diversity of crops, required about $27 \%$ more hours of work than the conventional. When this higher labor requirement was factored into the economic analysis, and the value of unpaid family labor was subtracted from gross profits, the organic farm returned only $\$ 2.49$ per acre more than the conventional one from 1986-90, and was $\$ 4.45$ per acre less profitable from 1991-95.These go well with findings of Pacini et al., 2003.

Because of the diversity of crops being grown and the need to balance soil fertility needs against income needs, the organic system also required more management skills than the conventional one. This was illustrated by the Farming System Trials project. Rotations and crop mixes changed through the years, as researchers experimented with ways to enhance the yields and frequency of cash crops, suppress weeds, and still maintain soil fertility.

\section{Yields}

The productivity of farmland-its yield of crops-is critical to meeting the world's need for agricultural products. It's also critical to the farmer's income, because prices for many farm crops are determined by factors out of the farmer's control. For those reasons, conventional farming systems had been designed to maximize yield.

Because organic systems require fewer purchased inputs, such as fertilizer and pesticides, it is possible for organic farms to provide net income comparable to conventional ones even if yields are somewhat lower. But the world's increasing food and fiber requirements suggested that if organic farming practices are to compete successfully with conventional practices, they must be capable of producing comparable yields [22,23].

Porter et al. [22]; Warman \& Havard [24] also suggested that, soils high in organic matter are better able to hold moisture and conserve when encountered with dry spells during the crop growth, relative to conventional systems. During 1995 a drought year, corn yields in the legume-based system recorded more than $22 \%$ as compared with conventional systems. Further, as well during 1994 (dry spells) during critical growth periods Corn yielded $36 \%$ more in legume-based system than conventional. Similar studies were also reported by Sean et al. [23].

Shortly before the Institute launched the Farming Systems Trial in 1981, the U.S. Department of Agriculture issued a report that emphasized the need for research to determine, why switching to organic farming resulted in lower yields. Providing an answer to that question was one of the primary goals of the trial in its early years (1981- 85/86). The three systems were designed to mirror three distinct types of farms-a conventional farm with a five-year cash grain rotation of corn and soybeans, an organic farm with livestock, which must include forage crops for its animals in its rotations, and an organic farm raising cash grains in rotation with green manures for soil fertility.

Yields in all three systems varied from year to year because of weather conditions, just as they do on commercial farms. Management decisions-when to plant, what variety to plant, and when to cultivate-also affected yield in some years [25]. Although the rotations differed between the three systems, field replications made it possible to directly compare crop yields. Corn was grown under some replications of each system every year, for example, even though some replications of the three systems might be growing soybeans, small grains, or forage crops that year according to their rotation plans.

\section{Corn yields}

As well known, of its high nitrogen requirement, corn was considered the benchmark crop for comparing differences between the three systems. For the first four years of the experiment, the two organic systems produced significantly lower corn yields than the conventional system. The first year, the legume-based system produced $56 \%$ of the conventional system's corn yield; the manure-based system produced $64 \%$ of the conventional yield. These are in tune with [26].

In all systems, the first year of corn followed a previous year's crop of wheat, which had been grown on the land before it was converted to an experimental site. Wheat, which does not fix nitrogen as leguminous crops do, contributed little nitrogen for the corn crop, and nitrogen for the conventional crop was supplied by commercial fertilizer. In 1985, when corn in the legume-based system followed a green manure crop of hairy vetch contributing an estimated $80 \mathrm{Kg}$ per acre of nitrogen, it yielded as well as the conventional system. Similar trend was also reported by Nguyen \& Haynes [26].

Overall, organic corn yields averaged 29\% lower than conventional yields in the years from 1982 through 1984. From 1986 through 1990, yields averaged 2\% higher in the manurebased system and $2 \%$ lower in legume-based system than the conventional system. In the last five years (1991- 95), yields in all systems had stabilized to comparable levels [9].

The low corn yields in the early years, followed by higher and stable yields in later years, is not solely related to the amount of nitrogen in the soil, as indicated by soil tests and measurements of nitrogen in corn ear leaves at various stages of growth. While there may have been sufficient nitrogen in the organic soils to produce reasonable corn yields, it was not yet in an available form that plants could use efficiently. Once the microbial activity in the soil reached a new equilibrium, the organic systems showed themselves capable of supporting corn yields equivalent to those in a conventional system [1]. 
But management abilities must not be discounted as a factor in maintaining yields in organic systems. In the early years, heavy weed growth in some of the organic plots contributed to low yields. As management practices improved and rotations were adjusted to help suppress weeds, competition from weeds for nutrients and moisture decreased. In some years, the legumebased system performed poorly because of other management decisions-late planting in one year to allow for more spring growth from a green manure crop, for example, and use of a short-season variety another year so that the corn crop would be out of the field in time to plant a winter wheat crop [1].

In 1982, for example, nitrogen concentration in corn leaves grown in the legume-based system was not significantly different from that in the conventional system, suggesting that the soil contained enough nitrogen for the corn. Still, the legumebased system produced $60 \%$ of the yield of the conventional system, partly because of excessive weeds and partly because it was planted to a short-season variety that is inherently less productive than a long-season one. These adjustments in farming practices make it more difficult to directly compare the performance of the three systems, but they are important to the overall goal of the Farming Systems Trial. The experiment was designed from the outset to operate as commercial farms would operate. An organic farmer, noting losses in yield from weeds or the use of certain varieties of corn, would surely change his or practices to prevent further losses.

The organic systems tended to produce better corn crops than the conventional system in dry years. Soil analysis also revealed that soils in the organic fields, having better soil structure, conserved and retained moisture for a considerable period of time in dry spells, and furthermore, better able to absorb and retain precipitation.

\section{Soybean}

Soybean yielded less in all systems in the first year, which was attributed to the seed inoculant that is commonly used to enhance the ability of legumes to fix nitrogen. Either not enough inoculant was used, or the powdered product used as seed coating was not viable enough for seed emergence. This problem was taken care of during latter years. As soybeans could fix their own nitrogen, yields were not affected by the lower nitrogen levels in the organic systems in the early years, as were corn yields [7].

However, in the first 10 years of the trial (1981-90) soybean yields in the organic systems were occasionally lower than in the conventional one, as researchers experimented with cropping methods and rotations to achieve the complementary goals of yield, income, soil fertility, and weed management. In the last five years, soybean yields had been stable across all systems [7].

Studies conducted elsewhere also documented that, average soybean yields in the manure-based system had been as high as those in the conventional system, even though the organic system tended to be weedier than the conventional, which applied herbicides. In the legume-based system, vegetables grown after soybeans intercropped with small grain crop, reduced soybean yield to about $85 \%$ of the yield, but increased vegetable yields and quality by about $45 \%$. The overall production loss in soybean was partly made up by vegetables, also grain crop suppressed weeds and contributed organic matter, hence the tradeoff was considered reasonable Teasdale et al. [27]; Xu et al. [28].

\section{Small grains and forage}

The conventional system, which followed a standard commercial rotation of corn and soybeans, did not grow small grains or forage crops such as hay or corn for silage. However, these crops were a part of the more complex rotations in the two organic systems.

The manure-based system required forage crops because of the need to produce feed for livestock. In the legume-based system, the experiment initially included forage crops in the rotation as a secondary cash crop, when the rotation did not call for corn or soybeans, as well as, for their value in contributing to soil fertility and weed suppression.

Because the conventional system did not grow these crops, it was not possible to directly compare yields from the organic systems to those in the conventional system. In general, yields of wheat, oats, barley, hay, and corn grown for silage rather than for grain were comparable to or slightly above the average for conventionally managed farms. Eventually, the extensive studies documented that, after a transition period of several years, the two organic systems were capable of crop yields comparable to those of the conventional systems $[29,30]$.

\section{Summary}

After an exhaustive review of work done for 15 years, certain long-term benefits of organic farming systems have been identified, given below:

a. Increase in soil organic matter (soil carbon) and nitrogen levels providing sustainability to the system;

b. Fossil energy inputs for organic crop production were about $30 \%$ lower than for conventional systems;

c. (c)After an initial 4-5 years of transition phase, organically managed crop yields were similar in reference to conventional systems;

d. Even though labor inputs were higher in organics, but they were evenly distributed throughout the year, as compared with conventional systems;

e. Because organic foods fetch higher market prices, net economic returns per hectare were often equal or higher than conventional production systems;

f. Crop rotations and cover cropping typical of organics reduced soil erosion, pest problems and use of chemicals; 
g. Presence of high organic matter conserved soil and water resources which proved very beneficial during drought years;

h. Recycling of livestock waste reduced soil pollution;

i. Presence of abundant biomass both above and below ground( soil organic matter) increased biodiversity, thus proving beneficial in biological pest control as well as, increased crop pollination by insects;

j. Organic farming technologies should be adopted by conventional practitioners making the system more viable, sustainable and ecologically sound for future of agriculture systems.

\section{References}

1. Pimentel D, Hepperly P, Hanson J, Douds D, Seidel R (2005) Environmental, Energetic, and Economic Comparisons of Organic and Conventional Farming Systems. Bioscience 55(7): 573-582.

2. Greene C (2005) US Department of Agriculture's Economic Research Service.

3. Altieri $\mathrm{M}$, Uphoff $\mathrm{N}$ (2001).Alternatives to conventional modern agriculture for meeting food needs in the next century. Cornell International Institute for Food, Agriculture Development.

4. Lal R (2003) Global potential of soil carbon sequestration to mitigate greenhouse effect. Critical Reviews in Plant Sciences 22(2): 151-184.

5. Lotter DW, Seidel R,l Liebhardt W (2003) The performance of organic and conventional cropping systems in an extreme climate year. American Journal of Alternative Agriculture 18(3): 146-154.

6. Hanson J, Lichtenberg E, Peters S (1997) Organic versus conventional grain production in the mid-Atlantic. An economic overview and farming system overview. American Journal of Alternative Agriculture 12(1): 2-9.

7. Hepperly P, Seidel R, Pimentel D, Hanson J, Douds D (2007) Organic farming enhances soil carbon and its benefits. Pages 129- 153 in Soil Carbon Management, Economic, Environmental and Societal benefits. In: Kimble J, Rice C, Reed D, Mooney S, Follet R, et al. (Eds.), CRC Press, Boca Raton, Florida, p. 268.

8. Franke- Snyder M, Douds DD, Galvez L, Phillips JG, Wagoner P, et al (2001) Diversity of communities of AM present in conventional versus low-input agricultural sites in eastern Pennsylvania, USA. Applied Soil Ecology 16: 35-48.

9. Drinkwater LE, Wagoner P, Sarrantonio M (1998) Legume-based cropping systems have reduced carbon and nitrogen losses. Nature 396: $262-265$

10. Wander M, Traina S, Stinner B, Peters S (1994) Organic and conventional management effects on biologically active soil organic matter pools. Soil Science Society of America Journal 58(4): 1130-1139.

11. Harris G, Hesterman O, Paul E, Peters S, Janke R (1994) Fate of legume and fertilizer nitrogen-15 in a long term cropping systems experiment. Agronomy Journal 86: 910-915.

12. Power JF, Wiese R, Flowerday D (2001) Managing farming systems for nitrate control: A research review from management systems evaluation areas. J Environ Qual 30(6): 1866-1880.

13. Galvez L, Douds DD, Wagoner P, Longnecker LR, Drinkwater LE, et al (1995) An overwintering cover crop increases inoculum of VAM fungi in agricultural soil. American Journal of Alternative Agriculture 10: 152-156.
14. Mader P, Fliebach A, Dubois D, Gunst L, Fried P, Niggli U (2002) Soil fertility and biodiversity in organic farming. Science 296(5573): 16941697.

15. Delate K, Duffy M, Chase C, Holste A, Friedrich H, et al. (2003) An economic comparison of organic and conventional grain crops in a long-term agroecological research site in Iowa. American Journal of Alternative Agriculture 18: 59-69.

16. Chavas JP, Posner J, Hedtcke J (2009) Organic and conventional production systems in the Wisconsin Integrated Cropping Systems Trial. Economic and Risk Analysis 1993- 2006. Agronomy Journal 101: 288- 295.

17. Cavigelli M, Hima B, Hanson J, Teasdale J, Conklin A, et al. (2009) Longterm economic performance of organic and conventional field crops in the mid-Atlantic region. Renewable Agriculture and Food Systems 24(2): 102-119.

18. Brumfield RG, Rimal A, Reiners S (2000) Comparative cost analyses of conventional, integrated crop management and organic methods. Hort Technology 10(4): 785-793.

19. Delate K, Cambardella CA (2004) Agroecosystem performance during transition to certified organic grain production. Agronomy Journal 96: 1288-1298.

20. Karlen DL, Duffy MD, Colvin TS (1995) Nutrient, labor, energy, and economic evaluations of two farming systems in Iowa. Journal of Production Agriculture 8(4): 540-546.

21. Roberts KJ, Warnken F, Schneeberger KC (1979) The economics of organic crop production in the Western corn belt. Agriculture Economics Paper No. 1979-6. Department of Agriculture Economics, University of Missouri, Columbia, USA, pp. 63-101.

22. Porter P, Huggins D, Perillo C, Quiring S, Crookston R (2003) Organic and other management strategies with two- and four-year crop rotations in Minnesota. Agronomy Journal 95: 233- 244.

23. Warman PR, Havard KA (1997) Yield and quality of organically and conventionally grown vegetables. Agriculture, Ecosystems and Environment 61: 155-162.

24. Hanson J, MusserWN (2003) An economic evaluation of an organic grain rotation with regards to profit and risk. Department of Agricultural and Resource Economics, University of Maryland, USA, pp. 3-10.

25. Nguyen ML, Haynes RJ (1995) Energy and labour efficiency for three pairs of conventional and alternative mixed cropping farms in Canterbury, NewZealand. Agriculture Ecosystems and Environment 52(2-3): 163-172.

26. Smolik JD, Dobbs TL, Rickert DH (1995) The relative sustainability of alternative, conventional and reduced tillage systems. American Journal of Alternative Agriculture 16: 25-35.

27. Teasdale J, Coffman C, Mangum R (2007) Potential Long-term benefits of no-tillage and organic cropping systems for grain production and soil improvement. Agronomy Journal 99: 1297-1305.

28. Xu HL, Wang R, Xu RY, Mridha MAU, Goyal S (2003) Yield and quality of leafy vegetables grown with organic fertilization. Acta Horticulturae 627: 25-33.

29. Cesare P, Wossink ADA, Giesen G, Vazzana C, Huirne R (2003) Evaluation of sustainability of organic, integrated and conventional farming systems: a farm and field-scale analysis. Agriculture- Ecosystems and Environment 95: 273-288.

30. Sean C, Klonsky K, Livingston P, Temple ST (1999) Crop-yield and economic comparisons of organic, low-input, and conventional farming systems in California's Sacramento Valley. American Journal of Alternative Agriculture 14: 109-121. 
This work is licensed under Creative Commons Attribution 4.0 License DOI: 10.19080/ARTOAJ.2017.06.555678
Your next submission with Juniper Publishers will reach you the below assets

- Quality Editorial service

- Swift Peer Review

- Reprints availability

- E-prints Service

- Manuscript Podcast for convenient understanding

- Global attainment for your research

- Manuscript accessibility in different formats ( Pdf, E-pub, Full Text, Audio)

- Unceasing customer service

Track the below URL for one-step submission https://juniperpublishers.com/online-submission.php 